\title{
27
}

\section{CROSS-CULTURAL IS ADOPTION IN MULTINATIONAL CORPORATIONS}

\author{
A Study of Rationality
}

Gamila Shoib and Joe Nandhakumar
School of Management, University of Bath, UK

Abstract: A common claim in the literature on Information Systems' implementation in the context of less developed economies or so-called "developing countries" is that the "Western" technology is at odds with the local cultural context, in particular it is believed to mismatch local rationality in the sense of the accepted ways of doing things. In this paper we investigate IS implementation in a company based in a "non-Western" context compared with IS adoption in another company in a "Western" country context. Seen as a particular form of decision-making, the adoption and implementation processes are analysed drawing on the literature on decision-making, rationality in "Western" and "non-Western" contexts. Presenting evidence from these two contexts we argue that multiple forms of rationality exist in any context and that national culture is only one aspect of actors' as well as researchers' sense-making of activities in any given context. Linking the cases back to the literature we reflect on the implications of our findings for cross-cultural research of IT implementation.

Keywords: Rationality, Decision Making, IS Adoption, Cross Cultural Management.

\section{INTRODUCTION}

Western ${ }^{1}$ knowledge and its model of rationality are usually presented in research on developing countries (DCs) as a homogenous body of knowledge, which dominates research and practice (Avgerou, 2000). Recent interpretive studies of Information Systems (e.g. Ciborra, 1999a), have

${ }^{1}$ The term "West" is used, as is commonly done in the "developing countries" literature and discusses at length in Said (1994), to refer to the "first world", namely Westerns and Central Europe as well as the USA. 
however challenged the domination of the rational model and its normative status as the accepted form of behaviour within its own Western context. Unlike conventional critiques, discussed later, these interpretive works, having lost the prescriptive normative view of research, allow for alternative perspectives to emerge. Such interpretive works allow researchers, especially in non-Western countries, to be more reflexive about what happens in organisations without the "pressure" of labelling it as "success" or "failure" because of its alleged mismatch with the accepted model. It allows them to move a bit further in the quest to understand rather than to prescribe behaviour.

This paper therefore first investigates the rational model and its critiques. Moving on the extension of the rational model to IS in DCs context is highlighted. This theoretical foundation is followed by a presentation of the empirical work, namely the two cases - Company $\mathrm{X}$ and Company $\mathrm{Y}$, representing the two contexts as well as the a) decision making in IS adoption and b) the rational model and technology as its instrument and symbol in action. The final section of the paper discusses the cases in terms of the literature and reflects on the implications for the way IS research, in particular in cross-cultural contexts, is constructed.

\subsection{Rationality and Decision-Making in Organisations}

In order to understand what it means for an organisation to be "rational", we build on reviews in the organisational behaviour literature of the rational model and its conventional critiques before moving on to present the alternative interpretive perspective. As Miller et al. (1996) argue, the majority of theories on decision-making in the literature adopt the positivist paradigm. In studying an organisation an attempt is typically made to locate its decision-making within one of the three choice paradigms: the (boundedly) rational model (Simon, 1976), the power and politics model (Pfeffer, 1981) or the garbage can model (Cohen et al., 1972).

Decision-making, has thus developed from a view of the process as a step by step logical and rational process to a process constrained by cognitive limitations, organisational constraints and finite resources. Considerations of group (ir)rationality as well as unstable and ambiguous conditions have brought in the political and garbage can perspectives (Eisenhardt and Zbaracki, 1992).

In a summary of themes of newer perspectives on Organizational Behaviour, Weick (1985) recognises the retrospective and political nature of 
rationality. Success is thus presented as a form of rationalisation/ legitimation. He recommends

"Don't treat rationality as a universal prescription. If you live by rationality alone, you lose options (use of intuition, quick response, trial and error) and you lose non-deliberate sources of variety (hunches)" (Weick, 1985: p.132).

Such a perspective can be seen as part of an emerging tradition reflected in the recent model put forth by Mintzberg and Westley (2001) that seeks to combine elements of two forms of rationality, one that is planned and another that is situated. Mintzberg and Westley's (2001) motivation for proposing this theory is the observation that the rational approach turns out to be uncommon. They recommend that the "thinking first" model of decision-making in organisations be supplemented with two different models "seeing first" (sudden insight) and "doing first" (trial-and-error) embracing intuitive and action-oriented forms of decision-making. Decision-making is done through discussion, collage and improvisation and incorporates emotions, humour, fear and anger. They conclude that there is a need to "put [thinking] in its place alongside seeing and doing" and that people in organisations combine all three. It would therefore seem futile to try to label organisations or individuals based on different types of rationality.

Finally, comparing the structure of improvisation with that of decisionmaking, Ciborra (1999a) concludes that each contains elements of the other. Reconciling the planned nature of decision-making and improvisation with the circumstantial interpretation of the past that gives ultimate meaning to action, The deep nature of decision-making is therefore one of improvisation (p.145). Elsewhere with his colleagues (Ciborra et al., 2000) argue for an alternate view that defies conventional management and IS wisdom.

\subsection{Interpretive Perspective on Rationality and Information Systems}

The rational choice model extends to the arena of Information Systems. Technology, seen as a tool for change and control (Avgerou, 2000; Ciborra and Hanseth, 2000), has been heavily implicated in the domination of the rational model in organisations. Some works, however, break with this functionalist tradition and are rooted in a more phenomenological, interpretive worldview. They offer alternate views of rationality. Suchman's (1987) work on plans and situated actions challenges the assumption of technology (and its use) as rational. Her work shows how the rationality of technology itself is an ascribed property given to it by human actors who 
label the machine as intelligent given the slightest signs of human intelligence. Her work attempts to subvert the common view of rationality in the rational choice theory of human action. The premise of Suchman's (1987) work is that all purposeful action is situated action. Accountability necessitates rationality and the retrospective use of plans to explain/justify actions. Plans, which hold the uncontested position of the correct form of action for a rational actor, are presented as retrospective rhetorical instruments of rationality. Her investigation of the project of building intelligent artefacts contributes to the notion of situated action and the problem of shared understanding.

Finally, Orlikowski (2000), like Suchman (1987) and also Ciborra's work, may be placed in the context of an increasing shift towards situated action and practice, e.g. Crossan et al. (1996) and Orlikowski (2000).

The literature on IS in DCs follows a very similar pattern to the field of IS at large where the mainstream is dominated by the functionalist views and a small stream of interpretive, context-sensitive studies exist. Studies of IS in "non-Western" countries affiliate themselves with, the cross-cultural and comparative management literature or international business literature. However, given technology's implication in the socio-economic development of DCs (Walsham, 2000), studies also appear as part of the development literature (Avgerou and Walsham, 2000). Global Information Systems are also a new theme for researchers on less developed economies. Unlike the situation of the dichotomy of the notion of culture studies on IS in international, cross-cultural and international settings are preoccupied with the notion of culture. The "culture-free" hypothesis is uncommon. The prevailing assumption therefore is that technology is "Western" and the context is culture- and country-specific and is predominantly studied by focusing on the values and beliefs held by individuals and groups within that culture (Abdul-Gader and Al-Bureay, 1993). Unlike management practices, which are, at times, viewed as universal, technology is almost always seen as "Western" (Shoib and Jones forthcoming). This may be again explained by technology's association with socio-economic development and as a symbol of rationality and progress.

As mentioned earlier, some research within the DCs literature is more interpretive and context-sensitive and recognises and celebrates situated local improvised practice in DCs. Most notable are the conference proceedings of IFIP 9.4 in 1998 in Bangkok and in 2000 in Cape Town, namely Avgerou and Walsham (2000) and Sahay (2000) respectively and the work of Appadurai (1996). The papers presented in the edited collections, despite their diverse topics and wide range of country coverage, are congruent with many of our findings. 


\section{RESEARCH SETTING AND APPROACH}

The research approach adopted in this study is interpretivism (Walsham, 1993). Interpretivism assumes that knowledge of the world is a social construction by human actors. Interpretive researchers therefore attempt to study phenomena from the perspective of the actors involved and to understand the meanings that individuals ascribed to them. This study aims to understand decision-making in IS adoption and implementation in a company based in a non-Western context compared with another company in a Western country context.

The main, larger-scale, study was carried out in the subsidiary of a USbased multi-national corporation in Egypt. A comparative study was carried out in the world head quarters (HQ) of a large manufacturing company (Company Y) in USA and offices and plants around the country. Both companies are volume manufacturer of high-value consumer products, which have operations in several countries and each employ several hundred thousand employees world-wide. The companies are highly structured, have a strong management hierarchy with several layers of senior executives.

\subsection{Data Collection}

The study at Company $\mathrm{X}$ involved one of the authors spent 9 months as a participant observer in the IT department in Egypt during 1997-1998. Additional data were gathered over a further period of 15 months (19981999) through email communication with members of the organisation, occasional visits and a formal workshop to discuss the findings. At least 88 unstructured and semi-structured interviews were held with all members of the IT and sales organisations to gain an understanding of the decisionmaking practices which inform IT use in the sales department, especially those relating to a sales force automation (SFA) project, which had taken place in October 1996 and was being upgraded during the field study. The interviews also included so-called practical sessions during which members of the organisation walked the researcher through their daily work and their usage of their laptops. During these sessions with the users copies of user files were taken onto individual floppy disks, both for reference as well as in preparation of the analysis.

Field observations of interactions with other members of the organisation including user support, chats, social events (e.g. lunch, coffee breaks), meetings etc. were logged into a self devised field-tracking-system shortly after they occurred. This fed into a "chronological events list" which served as a filter/index to the wider set of observations and was crucial in the selection of the "significant" situations, which were selected for closer 
analysis. A field/personal diary was also written periodically to supplement the formal material gathered and provide reflections on the research as a whole. Further electronic documents received via email and pertaining to all aspects of the organisation and its employees were also retained.

At Company $\mathrm{Y}$ the data collection was conducted through over 30 unstructured interviews with organizational members and by observation of their organizational practices at the world HQ in USA and offices and plants in the South of USA from 1997 to 1998. Interviewees included senior executives who led the technology project implementing Internet-based information systems from the USA, many IT and functional managers from the USA and UK. Most of the interviews were tape-recorded and transcribed. Documents have also been examined, including promotional documentation, training manuals and Internet-based support documents. Detailed field notes were maintained during the study period to record observations and events during each visit. Additional data were gathered during 1998-2002 through occasional visits and workshops.

\subsection{Data Analysis}

The material gathered was partly imported into a qualitative data analysis package (NUD*IST) and examined to identify comments and actions of the participants that reflected similar views with respect to IT implementation (Glaser and Strauss, 1967). The iterative examination of interview statements, comments and observed interactions of participants from each company led to the identification of a set of themes that reflected multiple interpretations held by members of each organization with respect to IT adoption. The analysis encouraged these themes to emerge from the data rather than imposing them on the data. In the case descriptions below extracts from the interviews are provided as examples to illustrate our arguments.

\section{CASE DESCRIPTIONS AND ANALYSIS}

\subsection{Company $\mathrm{X}$}

The sales department of Company $\mathrm{X}$ was based in a modern office block in Cairo. The building also housed the IT department, including the support staff, who ran user training and the help desk. In 1996 the Company X issued its salesmen with laptop computers, so that they could work from home, downsizing its Cairo headquarters and closing its regional depots. As part of the sales force automation (SFA) project, field sales staff (customer 
business managers, as they were called), were given training on the system (mainly introduction to the laptops and Microsoft Office applications) by an outsourced third party.

According to IT management, the SFA project had little effect on business processes, as the primary objective appears to have been the introduction of the computers themselves. It was left to the sales force to "export" their practices to the system. At a later stage in the project, however, a shipment reporting tool was introduced, which allowed the sales organisation to run queries on it. The interviews revealed that many of the salesmen had great difficulty in using the SFA due to the generic character of the training, the use of an English language interface (when most were Arabic speakers) and decentralisation of report and data generation (previously done by secretaries). As a result, the computers were seen as a "burden" and most salesmen used them as little as possible. IT staff attributed these difficulties to the sales field staff's lack of computer literacy and ways of thinking.

"They're not very computer literate that is. Look sales users, sales people in general they do not have strong thinking and problem solving... So they just know enough to keep their work going" - [IT Manager].

"Yes, it's my feeling from the way they operate the machine. They just don't know what's going on. They memorise but they don't understand that is" - [IT Manager].

Field sales people were seen to be ill educated (with no university degrees), and reliant on memory rather than understanding, especially compared to IT staff who were predominantly Engineering graduates. One expression of this difference was evident in language, where the IT staff tended to be fluent in English and mix Arabic and English in one sentence whereas field sales spoke only Arabic. This was significant, as language and computer knowledge were heavily implicated in performance evaluations and closely linked to promotion:

"English has to be important for us ... if I am going to be in charge of a new job or will move up with a higher promotion or so, I have to ... suppose the department head is an Englishmen or Spanish or any other nationality ... how will I deal with him? I will never get promoted unless I am perfect in English." - [Area Manager, Alexandria and Delta region].

Further informal hierarchies were evident within the sales force between those based in Cairo and those "in the provinces" and within the company as 
a whole between graduates of the American University in Cairo and graduates of other universities.

The salesmen, on the other hand, considered that the IT staff, working regular office hours in a peaceful, air-conditioned building in Cairo, had little appreciation of the working conditions in which salesmen were expected to use their computers. Spending their days in the heat, dust and noise, travelling long distances over poorly-maintained roads to visit unruly customers in remote locations was very different from the protected "calm" and order of the head office environment where they had been trained:

"there is a problem between us. They are people who look at us as negligent with the machines, that we ... do not use them well and consequently you feel when we deal with them that they are fed up of us ... And then at the same time, something could happen incorrectly, unintentionally because I don't understand. If you explained to me correctly from the beginning, I will not do anything wrong" - [Area Manager, Alexandria and Delta region].

This situation was further exacerbated by the fact that none of the IT staff had completed their orientation session and been to the field with a salesman. These same "ignorant" salesmen, however, present a very different picture if we examine them in interaction with their customers. Here they appear as the rational, technologically capable ones, seeing themselves as superior to their customers because of their (company's) "scientific" ways of doing business, and dismissive of what they see as their customers' backward baladi ${ }^{2}$ business practices:

"Because you are really dealing with a type of people who are not human. You could be dealing with someone who at most can count cases and money. That is all his interaction with the world through these two things only" - [Area Manager, Cairo and Canal region].

"We are not sitting at the corner of an alley... [The customer] upset me. "If I fill the boot of the car with product" and stuff like that. I told him "No this is in Baladi. No we want numbers" - [Area Manager, Cairo and Canal region].

They were also amused by their customers' lack of computer knowledge:

2 An Egyptian term, literally "my country" and associated with awlad el balad or "the sons of the country", referring to people who follow and preserve the old Egyptian ways (El Hamamsy 1985 , p. 56). 
"I once went with it to the field. It was the first time ... for them they were seeing a bag like that with a computer coming out of it ... So while I was standing talking to the customer, another one of our customers was calling him, telling him " $\mathrm{MrX}$ will come to you and is bringing the computer for you with him. And you'll see your numbers and you'll see whatnot, and the screen is like the television". So I went and found him all dressed up and elegant and sitting there. And he brought his brothers and relatives and was sitting waiting" - [Area Manager, Cairo and Canal region].

This salesmen's scorn for their customers, however, also reflected a concern with keeping the upper hand in the relationship:

"So the customer... when the customer finds an opportunity to feel that I don't understand, he attacks me, because I am always sitting on top of him... So when he finds an opportunity to escape me and feel that I don't understand, ... I am unable to control him. So he must feel continuously that I understand" - [Area Manager, Cairo and Canal region].

In this, the computer could sometimes be an important tool. Even though most salesmen shied away from taking the laptops with them to the customers (perhaps because they were concerned that the customer would sense their incompetence and hesitation in front of English error messages) they regularly took computer print outs (often produced by a more knowledgeable colleague as a favour) using them for "objection handling" and as the last word if a dispute should arise with a customer.

"If you have your facts and figures, pretty much, you're just so powerful. And you're even so much more powerful than the customer himself.. Because you know when he tells you that "Look this is too much for me, I can't take that much", "Why can't you take that much", you know because you've got the computer print out and it shows you the last few months, past six months and the same a year ago and pretty much the numbers can beat him. You know, he can't complain" - [Area Manager, Cairo and Canal region].

But the salesmen also recognised that there were limits to what computers could do for them.

"So there are different circumstances with the customers that the computer cannot understand. Because it is only numbers and information" - [Area Manager, Cairo and Canal region]. 
Despite the computer's importance as a means of persuasion with the customer, therefore, the key to successful selling was still seen to be practical experience and knowledge of the market or the suq, in which the computer's role was restricted to very much a secondary role as the source of shipment data. Thus the salesmen's view of computers was often ambivalent. On the one hand they were a valued tool that supported the salesmen's sense of superiority over their customers, while on the other, they were not just a reminder of their marginality from the "westernised", modern world of the head office, but also a "burden", of limited use in some of the most important aspects of the salesman's work. However, the salesmen coped with their lack of training by relying on an informal network of more computer-literate friends as well as improvising and tinkering while using their laptops.

\subsection{Company Y}

At Company Y a dedicated IT Division based in the World HQ in the Midwest of USA was responsible for implementing a new internet-based system. This system was implemented to facilitate a global restructuring initiative involving a major plan to merge company's operations carried out separately in various parts of the world into one giant global company. Initially the new IT Division implemented a standardized network (based on TCP/IP) to link-up every computer within Company Y. Many engineers from the HQ Product Development Division who were experimenting with the free web browser made use of the newly implemented network, for example, for publishing technical documents and tracking project status. The IT Division managed the new system centrally, by requiring other divisions to place data content in servers located in the world HQ.

Senior executives from the HQ were able to use browsers for accessing and publishing technical documents and tracking project status. Many managers from Product Development Division claimed that the new systems saved travel costs, as they were able to share engineering drawings and visual images online with team members in other countries.

As these new systems became established in the company, the IT Division began to replace most of the legacy systems such as EDI with Internet systems in order to interact with suppliers. Many senior managers became technological evangelists, promoting the use of systems:

“... part of our mission is to be technology advocates and evangelists; part of our mission is to be educators; part of our mission is to be developers; part of our mission is to be infrastructure developers. We 
have, you know, quite a mixed bag of things that we're responsible for" [Head of IT Division].

While executives from HQ vigorously promoted Internet-based systems within the assembly plants, the systems staff at the plants considered that the IT Divisions from the HQ had little appreciation of their systems needs. Plant systems managers often joked how ignorant HQ systems staff. Many of the managers from assembly plants felt that the Internet initiative was imposed on them by the head office. Executives at HQ however felt that compared to staff at the HQ the staff at plants were incompetent, middleaged managers who were not comfortable with advances in technologies.

“...we actually have tried a couple of times with true collaboration like news groups and stuff like that [for plant engineers]. It hasn't been as successful - it's a cultural thing. I think there's a tremendous amount of value in a newsgroup ... facilitating a newsgroup, but our culture is just that they just weren't very well accepted. Part of it's a typing things. Part of it's we get a lot of middle aged and above people; some of them aren't comfortable with it. The secretaries tend to use it pretty well and those are good. But, well, we've had at least two attempts to try to get that into the engineering community. It just hasn't been real successful" - [Head of IT Division - Recalling with frustration].

Although assembly plants were a big challenge for HQ systems managers, they proceeded with their strategy to implement global Internet infrastructures. The IT Division insisted that anyone could use the internetbased system. Plant managers however found it hard to make use of the new systems without any training and they often forgot password and procedures to gain access to HQ systems. They had to rely heavily on their personal assistants for generating printouts of necessary reports from HQ systems that were routinely used in the plant meetings and negotiations:

"he [the plant manager] has a new computer on his desk, but very seldom does he do anything other than look at our production coun], there is a programme with production [local] counts on it, he will look at that and see what the hourly rate is coming out at" - [Systems analyst from an assembly plant in the South of USA].

On the other hand, the plant managers gave a different impression in their dealings with the workers in the plant. For example, the plant managers were seen as technically competent and promoted technological advances in the plant. A senior staff from a plant revealed that he was thrilled to take instructions from his plant manager who did "picture talk" [video 
conferencing] with him from the HQ. The workers in that plant were impressed with the plant manager's technological accomplishment. On the other hand the plant workers were seen as incompetent by their managers. For plant managers the information generated by these systems was extremely valuable in sustaining their managerial status locally, while on the other hand, this was also reinforcing their inferior status in their relationship with HQ executives.

\section{DISCUSSION}

Drawing on local descriptions of Egyptian society, e.g. El Hamamsy (1985) and Amin (2001), it is possible to identify two systems of (perceived) rationality: planned and situated. This situated rationality viewed from the point of view of the planned rationality can be seen as irrational, informal, and $a d$ hoc. The story told by case $\mathrm{X}$ is one of individuals playing multiple roles in multiple spheres of interaction with various interests and degrees of conscious deliberation and knowledgeable action. The dominating theme, however, also described persistently in most discussions of Egyptian society (e.g. El Hamamsy 1985; Amin 2001) is that of "Westernisation" and/or "Egyptianisation". It is a theme that appears to be as formative of individuals' assertion of their identity as it is of society as a whole as well as the research scene at large. In their various roles the actors draw on normative models of behaviour that are most pertinent to their situation. The "Western" model of planned rationality and a local model of situated rationality were identified as relevant to actors' sense-making. This analysis is supported by the discussions of society at large (El Hamamsy, 1985), which differentiate between "Westernised" individuals and "baladi" traditionalist Egyptians. Technology, as a symbol of "Western" rationality, played an important part in the projection of a "rational", "Westernised" image. This was particularly visible in focusing on the salesmen and their interactions in different realms, with the IT staff and with the customers. In their interactions with the IT staff they were the "irrational" incompetent users who were baladi in their ways and lacked problem solving skills and rationality. In their interactions with the customers they drew status from their use of technology (or image of so doing). In other situations they could chose to project an image of an "Egyptian" and disassociate themselves from the "Western" multinational.

If we focus only on the relationship between IT staff and salesmen then it would be easy to conclude that the salesmen were seen as irrational, unplanned and inferior. It would then be easy to see many examples that might seem to confirm the cultural characteristics identified by writers such 
as Hofstede (1980) and Trompenaars and Hampden-Turner (1998). But if we broaden the scope to include the Helpdesk's managers and the salesmen's relationship with their customers then the picture becomes somewhat different. One of the pair is seen to be "irrational", traditional, deferential and personalised. However, the same person can be simultaneously at both ends of the spectrum, depending on which relationship is being examined. This fits less well with these cultural typologies. Thus with IT staff, salesmen were the irrational traditionalists, while they, in turn, made similar remarks about their customers. IT managers made similar comments about the Helpdesk staff etc. The image of managers presented in the literature may therefore be described as one-dimensional and simplistic.

Local culture, which has been said to emphasise a situated rationality characterised by an appreciation of practical thinking, bricolage, improvisation and group loyalty, when viewed without the pressure of the "Western" rational normative model proves itself to be a facilitator and even "saviour" of business when the planned rational model "breaks down". It is therefore possible to argue that success, failure, and breakdowns are all relative constructs rooted in a particular worldview and perception of rationality. When one breaks down, the other, which is concurrently operative, becomes more visible. Researchers presenting and analysing such cases are also implicated in constructing and de-constructing these worldviews.

The story told by case $\mathrm{Y}$ is that IT adoption was situated everyday decision-making although there was evidence of rational decision-making, especially in action plans and peoples' accounts of adoption process and rationalizations of them. Many of the decisions were guided by individual's preference and mutual accommodation and negotiation, characterized by opportunism and improvisation (Ciborra's, 1999).

There was also evidence of decisions guided by actions and evolving conditions rather than preferences. Initially there were no intentions to allow users from Product Development division to develop their systems but with the implementation of Internet infrastructure it wasn't possible to stop this from happening. The unintentional nature of many of such decisions seems to imply a "garbage can" (Cohen et al., 1972) and situated form. The managers from HQ IT Divisions reacted to problems and their actions were situated and contextual.

Similar to case $\mathrm{X}$ we could make the same argument about the competing planned and situated rational models, which were used by actors as a resource for the purpose of rationalization. HQ executives' view was that the slow adoption of Internet-based IS at assembly plants was a 'cultural thing' and the 'middle-aged and above' plant managers were not comfortable with new IT. Similar to Sales Force in case X, the interactions of the assembly 
plant managers with the HQ executives and plant workers is a good example of individuals being at both ends of the rationality spectrum and their use of their position to further their situated interests in a particular context.

\section{CONCLUSIONS AND REFLECTIONS}

This paper has sought to further our understanding of IS implementation in cross-cultural, international settings. By drawing on an in-depth analysis of IS implementation in a company based in a non-Western context compared with another company in a Western country context, the paper argues that multiple forms of rationality exist in any context and that national culture is only one level of actors' as well as researchers' sensemaking of activities in any given context.

Our first reflection is on the treatment of technology in the cross-cultural and international context. The literature treats technology as "superior" or "Western" and the context is almost always assumed to be culture- and country-specific. It is predominantly studied by focusing on the values and beliefs held by individuals and groups within that culture (e.g. Abdul-Gader and Al-Bureay, 1993). A more helpful approach would seem to be to avoid treating IT as a tool with unambiguously positive associations and question the prevailing assumption that "traditional" ways are necessarily negative, inferior and irrational and at odds with this allegedly "Western" technology.

Our second reflection is the normative nature of the "success" model used to evaluate IS implementation especially in the context of less developed economies. Case $\mathrm{X}$ argued for a situated and relative definition of success and one that does not necessarily see local culture and context as an impediment to implementation. Success of IS implementation in organisations, therefore, needs to be understood as being the product of relationships between social actors who sustain and/or transform them in the course of their interactions. IS implementation success is a relative construct (Avgerou, 2000) and a function of chosen theoretical and analytical perspectives (see e.g. Bada, 2000). Researchers therefore need to be sensitive to the multiple roles and social positions at play in the various contexts as well as the multiple rationalities and alternative perspectives on success and failure available to actors and researchers alike.

Our third reflection is concerned with human agency. Evaluations of local situated culture would seem only able to see it as benchmarked against an idealised, normative model, which, as shown, may be largely more of a political legitimation instrument. It would also seem naïve to suggest that knowledgeable actors are unaffected by the multitude of cultural, and otherwise, influences available to all of us in our everyday life. Rationalities, 
as generally representative of different ways of doing things, are therefore a resource for actors to draw on in their everyday actions and sense-making of them. There is therefore a need to take account of the reflexivity of actors and their ability to transform or introduce change or act differently. This recognition would allow for the inclusion of "alternate" rationalities, which get drawn on according to the situation in order to advance actors' political interests. Individuals in different contexts thus play multiple roles in multiple spheres of interaction with various interests and degrees of conscious deliberation and knowledgeable action.

The final reflection is on analytical dualisms often adopted in IS research in this context and in general. The findings illustrate a point made by Giddens (1984) with regard to "discursive penetration" (social actors' awareness of their engagement in social reproduction and production) which leads to a "double hermeneutic" where the concepts of the sociological observers are constituted as meaningful by social actors and can become part of the actors' sense-making. The "West/non-West" dichotomy as well as the normative rational model are not theoretical constructs about developed and developing economies and societies or decision-making in organisations, but can also be said to exist in the minds of policy makers and actors and to play a part in their sense-making of their own actions and the assertions of their identities. It is therefore important for researchers to be clear on their own positions with regard to such devices while remaining open to the social actors' own interpretation of such constructs. Researchers therefore need to be clear on their own as well as actors' positions with regard to dualisms at hand. In this context we have identified three such dichotomies and transformed them into dualisms: West/non-West, developed/developing countries, and finally planned vs. situated action.

\section{REFERENCES}

Abdul-Gader, A. H. and Al-Bureay, M. A. "An Islamic Perspective to Information Technology: Management Implications", in Proceedings of the Arab Management Conference, Bradford, UK, D. T. H. Weir and M. J. Alwani (eds.), 1993.

Amin, G. Whatever Happened to the Egyptians? Changes in Egyptian Society from 1950 to the Present, American University in Cairo Press, Cairo, 2001.

Appadurai, A. Modernity at Large: Cultural Dimensions of Globalization, University of Minnesota Press, Minneapolis, 1996.

Avgerou, C. "Recognising Alternative Rationalities in the Deployment of Information Systems", Electronic Journal on Information Systems in Developing Countries, (3), Paper 7, 2000, pp. 1-17.

Avgerou, C. and Walsham, G. (eds.). Information Technology in Context: Studies from the Perspective of Developing Countries, Ashgate: Aldershot, 2000. 
Bada, A. O. "'Actually Existing Globalization': A Case Study of IT and Organizational Change in a Nigerian Bank", in Information Flows, Local Improvisations and Work Practices, IFIP WG 9.4 Conference, Cape Town, S. Sahay (ed.), 2000.

Cohen, M. D., March, J. G. and Olsen, J. P. "The Garbage-can Model of Organizational Choice", Administrative Science Quarterly, (17), March, 1972, pp. 1-25.

Ciborra, C. U. "A Theory of Information Systems Based on Improvisation" in Rethinking Management Information Systems, W.L. Currie, and B. Galliers (eds.), Oxford. Oxford University Press, 1999.

Ciborra, C. U. and Hanseth, O. "Introduction: From Control to Drift" in From Control to Drift: The Dynamics of Corporate Information Infrastructures, C.U. Ciborra et al. (eds.), Oxford. Oxford University Press, 2000.

Ciborra, C. U., Braa, K., Cordelia, A., Dahlbom, B., Failla, A., Hanseth, O., Hepsø, V., Ljungberg, J., Monteiro, E. and Simon, K. A. From Control to Drift: The Dynamics of Corporate Information Infrastructures, Oxford. Oxford University Press, 2000.

Crossan, M. M., White, R. E., Lane, H. W. and Klus, L. "The Improvising Organization: Where Planning Meets Opportunity”, Organizational Dynamics, (24:4), 1996, pp. 20-35.

Ein-Dor, P., Segev, E., and Orgad, M. "The Effect of National Culture on IS: Implications for International Information Systems", Journal of Global Information Management, Winter, 1993, pp. 33-44.

Eisenhardt, K. and Zbaracki, M. J. "Strategic Decision-Making", Strategic Management Journal, (13), 1992, pp. 17-37.

El-Hamamsy, L. "The Assertion of Egyptian Identity" in Arab Society: Social Science Perspectives, N.S. Hopkins, and S. E., Ibrahim (eds.), Cairo. The American University in Cairo Press, 1985.

Glaser, B. and Strauss, A. L. (1967). The Discovery of Grounded Theory: Strategies for Qualitative Research, Chicago: Aldine, 1967.

Hofstede, G. Culture's Consequences: International Differences in Work-related Values, London: Sage, 1980.

Khalil, O. and Elkordy, M. "The Relationship of Some Personal and Situational Factors to IS Effectiveness: Empirical Evidence from Egypt", Journal of Global Information Management, Spring, 1997, pp. 22-34.

Miller, S. J., Hickson, D. J. and Wilson, D. C. "Decision Making in Organizations", in Handbook of Organization Studies, S. R. Clegg, C. Hardy, and W. R. Nord (eds.), London. Sage, 1996.

Mintzberg, H. and Westley, F. "Decision Making: It's Not What You Think". MIT Sloan Management Review, (42:3), 2001, pp. 89-93.

Orlikowski, W. J. "Using Technology and Constituting Structures: A Practice Lens for Studying Technology in Organizations", Organization Science, (11:4), July-August, 2000, pp. 404-428.

Pfeffer, J. Power in Organizations, Marshfield, MA.: Pitman, 1981.

Sahay, S. "Information Flows, Local Improvisations and Work Practices", IFIP WG 9.4 Conference, Cape Town, 2000.

Said, E.W. Culture and Imperialism, London: Vintage, 1994.

Schutz, A. The Phenomenology of the Social World, Evanston, Ill.: Northwestern University Press, 1967.

Shoib and Jones (forthcoming). "Focusing on the Invisible: The Representation of IS in Egypt", Information Technology and People.

Simon, H. A. Administrative Behaviour, $3^{\text {rd }}$ Edition, New York: Free Press, 1976. (First edition published 1945). 
Suchman, L. Plans and Situated Actions: The Problem of Human Machine Communication, Cambridge: Cambridge University Press, 1987.

Trompenaars, F. and Hampden-Turner, C. Riding the Waves of Culture: Understanding Cultural Diversity in Business, London: Nicholas Brealey Publishing, 1998.

Walsham, G. Interpreting Information Systems in Organizations, Chichester: John Wiley and Sons, 1993.

Walsham, G. "Globalization and IT: Agenda for Research" in IFIP TC8 WG8.2: International Working Conference Aalborg, Denmark, R. Baskerville, J. Stage, and J. I. DeGross (eds.), Boston: Kluwer, 2000.

Walsham, G. Making a World of Difference: IT in a Global Context, Chichester: John Wiley, 2001.

Weick, K. E. "Sources of Order in Underorganized Systems: Themes in Recent Organisational Theory" in Organization Theory and Inquiry: The Paradigm Revolution, Lincoln, Y. (ed.), Beverly Hills: Sage, 1985.

\begin{abstract}
About the Authors
Gamila Shoib is a Lecturer in Information Systems at the University of Bath, School of Management, United Kingdom. She was born in Alexandria, Egypt and obtained her PhD in Information Systems from the University of Cambridge, Judge Institute of Management. She was raised in Egypt and currently lives in England. Her research interests focus on social and organisational aspects of the development and use of Information Systems in organizations especially in cross-cultural contexts including less developed economies. Gamila can be reached by e-mail at G.M.Shoib@bath.ac.uk or through her homepage on www.bath.ac.uk/ mnsgmas/.

Joe Nandhakumar is a Senior Lecturer in Information Systems at the University of Bath, School of Management, United Kingdom. He was raised in India and Sri Lanka and currently lives in England. Joe gained his $\mathrm{PhD}$ in Information Systems from the University of Cambridge, Department of Engineering. His primary research interest focuses on social and organisational aspects of the development and use of Information Systems. Joe can be reached by e-mail at j.nandhakumar@bath.ac.uk or through his homepage www.bath.ac.uk/ mnsjn/.
\end{abstract}

